\title{
Duygu İçerikli Sözcüklerden Oluşan Türkçe DRM Listelerinin Geliștirillmesi
}

\section{Development of Turkish DRM Lists with Emotional Words}

\author{
Elif Yüvrük ${ }^{\circledR}$, Haki Turan² ${ }^{\circledR}$, Aycan Kapucu ${ }^{3}$ (]
}

Teşekkür: Veri toplama sürecindeki katkılarından ötürü Başak Özkara'ya teşekkür ederiz.

${ }^{1}$ Arş. Gör., Ege Üniversitesi, Edebiyat Fakültesi Psikoloji Bölümü, İzmir, Türkiye ${ }^{2}$ Ege Üniversitesi, Edebiyat Fakültesi Psikoloji Bölümü, İzmir, Türkiye

${ }^{3}$ Dr. Öğr. Üyesi, Ege Üniversitesi, Edebiyat Fakültesi Psikoloji Bölümü, İzmir, Türkiye

ORCID: E.Y. 0000-0001-7150-4060

H.T. 0000-0002-0717-8018;

A.K. $0000-0001-7340-9876$

\section{Sorumlu yazar/Corresponding author:} Elif Yüvrük,

Ege Üniversitesi, Edebiyat Fakültesi Psikoloji Bölümü, İzmir, Türkiye

E-posta/E-mail: elif.yuvruk@ege.edu.tr

Başvuru/Submitted: 15.03.2019 Revizyon Talebi/Revision Requested: 03.05.2019

Son Revizyon/Last Revision Received: 18.07.2019

Kabul/Accepted: 29.07.2019

Online Yayın/Published Online: 14.10 .2019

Atıf/Citation: Yuvruk, E., Turan, H., Kapucu, A. (2019). Duygu içerikli sözcüklerden oluşan Türkçe DRM listelerinin geliştirilmesi. Psikoloji Çalışmaları - Studies in Psychology, 39(2): 245-266.

https://doi.org/10.26650/SP2019-0026

\section{öz}

Deese-Roediger-McDermott (DRM) paradigmas1 (Deese, 1959; Roediger ve McDermott, 1995), anlamsal ilişkili sözcük listelerinin ortak olarak çağrıştırdığı ancak gerçekte hiç görülmemiş sözcüğe dair güçlü bir bellek yanılması yaratmaktadır. Gözlenen bellek yanılmasının oldukça güçlü olması literatürde bu paradigmanın sıklıkla kullanılmasını, farklı değişkenlerin bu yanılmaya etkisinin incelenmesini ve farklı dillerde DRM listelerinin geliştirilmesini sağlamıştır. Geliştirilmiş olan mevcut DRM listelerinde bellek yanılmasını etkileyebilecek bazı sözcük özellikleri (Örn., somutluk, sıklık, imgelem gücü vb.) kontrol edilmesine karşın, sözcüklerin duygusal değerlikleri sıklıkla göz ardı edilmiştir. Bu çalışmanın amacı, çeşitli sözcük özellikleri açısından kontrol edilmiş pozitif, negatif ve nötr duygu içerikli sözcüklerden oluşan Türkçe DRM listelerinin literatüre kazandırılmasıdır. Bu amaçla, her üç duygu koşulundan 10'ar adet DRM listesi geliştirmiştir. Listelerin bellek yanılması oluşturma yüzdeleri tanıma belleği görevi kullanılarak ölçülmüştür. Tanıma belleği görevinden elde edilen veriler iki şekilde analiz edilmiştir. İlk olarak katılımcıların isabet ve yanlış alarm oranları analiz edilmiş, katılımcılarda her üç duygu koşulunda genel olarak başarılı bir şekilde bellek yanılması ortaya çıkartılabildiği görülmüştür. Ardından, geliştirilen her bir DRM listesinin etkililiği incelenmiştir. Bulgular, her üç duygu koşulunda geliştirilen DRM listelerinin başarılı bir şekilde bellek yanılması oluşturabildiğini, gözlenen etkilerin uluslararası liste geliştirme çalışmalarıyla uyumlu olduğunu göstermiştir. Negatif listeler ortalama \%66, pozitif listeler \%65 ve nötr listeler \%58 oranında bellek yanılmasına yol açmıştır. Çalışmada geliştiren duygusal DRM listelerinin, başta bilişsel psikoloji olmak üzere psikolojinin farklı alanlarında duygu ve bellek yanılmasını inceleyen araştırmacılara fayda sağlayacağı düşünülmektedir.

Anahtar Kelimeler: DRM, bellek yanılması, duygu, değerlik, uyarılmışlık 


\section{ABSTRACT}

The Deese-Roediger-McDermott (DRM) paradigm (Deese, 1959; Roediger \& McDermott, 1995) creates strong false memories of critical words that are actually never studied but are associated to a semantically-related studied word list. The fact that the created memory illusion is quite powerful has led to the frequent use of this paradigm to investigate effects of different variables on this illusion and to develop DRM lists in different languages. The present study aimed to develop Turkish emotional DRM lists including positive, negative and neutral words that are matched on arousal and on several other word characteristics. Ten DRM lists were created in each emotion condition (negative, positive, neutral); each list included ten list words related to one critical lure. Recognition memory test was used to measure the magnitude of false memories. Analyses of participants' hit and false alarm rates revealed that similar levels of false memories were created in each emotion condition. Levels of false memories for each critical lure were then calculated separately. The data showed that each DRM list was able to produce comparable levels of false recognition when compared to previous studies in the literature. Sixty-six percent of the negative critical lures, $65 \%$ of the positive critical lures and $58 \%$ of the neutral critical lures were recognized by the participants as old words. We believe that these emotional DRM lists would be useful for researchers working in different areas of psychology who are interested in investigating emotion and false memories in native Turkish-speakers.

Keywords: DRM, false memory, emotion, valence, arousal

\section{EXTENDED ABSTRACT}

The Deese-Roediger-McDermott (DRM) paradigm (Deese, 1959; Roediger \& McDermott, 1995), is frequently used to experimentally create false memories. In a typical procedure, semantically-related word lists are studied, each of which is associated with one non-presented critical theme word, followed by a recall or a recognition test. Participants frequently report non-presented critical words at comparable levels with studied words (Roediger \& McDermott, 1995). Even if participants are warned about the nature of the DRM effect, false memories for critical lures are almost inevitable (McCabe \& Smith, 2002; McDermott \& Roediger, 1998). The fact that the created memory illusion is quite powerful has led to the development of various sets of DRM lists in different languages.

One of the most frequently used DRM lists was created by Stadler, Roediger, and McDermott (1999). Some researchers have used Stadler et al.'s (1999) DRM lists by translating them into their own language (e.g., Anastasi, Rhodes, Marquez, \& Velino, 2005, Spanish; Mısırlısoy, 2004, Turkish; Stein \& Pergher, 2001, Brazilian Portuguese; Zeelenberge \& Pecher, 2002, Dutch). In fact, translating DRM lists into different languages could potentially impair associations within list words (Anastasi, Rhodes, Marquez, \& Velino, 2005). To overcome this problem, researchers have developed various original DRM lists in accordance with unique word characteristics in their own language (e.g., Anastasi, De Leon, \& Rhodes, 2005, Spanish; Cadavid \& Beato, 2017, Spanish; Göz, 2005, Turkish; lacullo \& Marucci, 2016, Italian). Yet, while some word characteristics (e.g., frequency of use, concreteness, etc.) were controlled 
in most of the developed lists, emotional valence and arousal of the words have often been ignored. Extensive research has demonstrated that these two dimensions of emotion substantially effect false memories (Dewhurst, Anderson, \& Knott, 2012; Gong, Xiao, \& Wang, 2016). To our knowledge, currently there are no emotional DRM lists available for use with native Turkish speakers. To this end, we aimed to develop Turkish DRM lists including positive, negative and neutral words that are matched on arousal.

\section{Method}

Ninety-two undergraduate psychology students (79\% women) with an average age of 21.14 years $(S D=1.83)$ participated in this study. Participants were not informed about the nature of the DRM task; neither before the study phase nor before the test phase. DRM lists were created by using the word norms of Tekcan and Göz (2005) for imaginability, concreteness, associations, and frequency, and norms of Kapucu, Kılıç, Özkılıç and Sarıbaz (2018) for valence and arousal. Ten DRM lists were created in each emotion condition (negative, positive, neutral); each list included ten list words related to one critical lure. To prevent high memory load, each participant was presented with five randomly selected DRM lists for each emotion condition, instead of all ten lists. All participants studied positive, negative, and neutral DRM lists in a counterbalanced order followed by a recognition test including studied/old words, critical lures and noncritical lures. For each test item, participants decided whether each item was old or new.

\section{Results}

A 3 (emotion: positive, negative, neutral) x 3 (word type: old, critical lure, noncritical lure) two-way repeated measures ANOVA was conducted on participants'"old" response rates (see Figure 1). As expected, false alarm rates ("old" responses to lures) for critical words ( $X=0.61$, $S S=0.19)$ were remarkably higher than those for noncritical words $(X=0.20, S D=0.13)$, showing false memory for critical words was successfully created in participants in each emotion condition $\left(F(2,182)=510.12, p<.001, \eta^{2}=.85\right)$. We then analyzed levels of false memories created by each DRM list, separately. To this end, we calculated the percentage of participants who gave an "old" response to each test word. A 3 (emotion: positive, negative, neutral) x 3 (word type: old, critical lure, noncritical lure) two-way between-subjects ANOVA was conducted on these old response rates (see Figure 2). Again, the significant main effect of word type $\left(F(2,138)=204.09, p<.001, \eta^{2}=.74\right)$ showed that old response rates for critical lures $(X=0.63, S D=0.17)$ were higher than those for noncritical lures $(X=0.20, S D=0.13)$. Sixty-six percent of the negative critical lures, $65 \%$ of the positive critical lures and $58 \%$ of the neutral critical lures were recognized by the participants as old words. 


\section{Discussion}

Emotional meanings of words are frequently ignored in false memory literature despite well-documented emotion-related effects. To our knowledge, this is the first study to develop Turkish emotional DRM lists including positive, negative and neutral words that are controlled on several word characteristics. Levels of false memories created by these newly developed DRM lists were satisfactory on each emotion condition and were comparable with existing studies in the literature (e.g., Stadler et al., 1999; Ulatowska \& Olszewska, 2013). We believe that these emotional DRM lists will be useful for researchers working in different areas of psychology who are interested in investigating emotion and false memories in native Turkish-speakers. 
Belleğimiz, geçmiş deneyimlerimizin bir kopyası değildir; yalnızca "kusurlu bir arşividir" (Brainerd ve Reyna, 2005, s. 4). Kimi zaman gerçekte hiç yaşamadığımız bir olay için dahi belleğimizde yanlış bir anı kaydedilebilir. Günlük hayatta deneyimlediğimiz söz konusu bellek yanılmaları laboratuvar ortamında sıklıkla Deese-Roediger-McDermott (DRM, Deese, 1959; Roediger ve McDermott, 1995) paradigmasiyla incelenmektedir (Örn., Gallo, 2004; Watson, Bunting, Poole ve Conway, 2005). Bu paradigmada kat1lımcılardan semantik olarak birbiriyle ilişkili bir dizi sözcüğü çalışması (Örn., dost, sırdaş, yakın, kardeş, yoldaş), ardından test aşamasında çalıştıkları sözcük listelerine ilişkin serbest hatırlama ya da tanıma belleği görevlerini tamamlamaları istenmektedir. Çalışmalardan elde edilen ortak bulguya göre katılımcılar, kendilerine sunulmamış olsa dahi sözcük setinin ortak olarak çağrıştırdığı kritik çeldiriciye (Örn., arkadaş) yönelik yanlış bir anı oluşturmakta, söz konusu kritik çeldiriciyi gördüklerini rapor etmektedirler.

DRM paradigmasında katılımcılarda sunulmayan kritik çeldiriciye ilişkin oldukça güçlü ve tutarlı bir bellek yanılması oluşturulmaktadır. Örneğin, kişilere çalışmanın doğası hakkında fikir vermek, yani çalışılan sözcük listelerinin kendilerine sunulmayan başka bir sözcüğü çağrıştırabileceğini ve test aşamasında buna dikkat etmeleri gerektiğini söylemek, bellek yanılmasını azaltmakla birlikte bu etkiyi ortadan kaldıramamaktadır (McCabe ve Smith, 2002; McDermott ve Roediger, 1998). Geri getirme aralığının uzadığ1 deneysel desenlerde liste kelimelerine yönelik bellek performansı düşerken, kritik DRM çeldiricilerine yönelik bellek yanılmalarının bozulmaması (Payne, Elie, Blackwell ve Neuschatz, 1996), hatta uzun süreli geri getirme aralığı sonunda (Örn., 1 hafta) kritik DRM çeldiricilerinin liste sözcüklerinden daha iyi hatırlanması (Thapar ve McDermott, 2001) bu paradigmada ortaya konan bellek yanılmasının oldukça güçlü olduğunu desteklemektedir. DRM'in kolaylıkla uygulanabilir bir görev olması ve yüksek deneysel kontrolün sağlanabilmesi bellek yanılması deneylerinde bu paradigmanın sıklıkla kullanılmasını sağlamıştır. Araştırmacılar yaşlanma, bireysel farklılıklar, duygu gibi psikolojinin çeşitli araştırma alanlarında bellek yanılmalarının rolünü incelemek için farklı niteliklerde DRM listeleri geliştirmişlerdir. Bu çalışmanın amacı Türkçe literatürde ilk kez, çeşitli sözcük özellikleri açısından kontrol edilmiş pozitif, negatif ve nötr duygu içerikli sözcüklerden oluşan DRM listelerini geliştirmektir. Geliştirilen DRM listelerinin, başta bilişsel psikoloji olmak üzere psikolojinin farklı alanlarında duygu ve bellek yanılmalarını inceleyen araştırmacılara fayda sağlayacağı ve Türkçe literatürde bellek yanılmalarına ilişkin çalışmaların yapılmasını kolaylaştıracağı düşünülmektedir. 


\section{Literatürde Geliştirilmiş Olan DRM Listelerinin Özellikleri}

Stadler, Roediger ve McDermott (1999) tarafından geliştirilen İngilizce DRM listeleri literatürde en sık kullanılan listelerdir. Araştırmacılar, Deese (1959) ve Roediger ve McDermott (1995) tarafından geliştirilen listelere ek toplam 36 liste geliştirmiş ve bu listelerin bellek yanılması oluşturma düzeyleri için norm değerlerini belirlemişlerdir. Serbest hatırlama görevinde kritik çeldiricilerin ortalama \%46's1 yanlışlıkla “daha önce çalışılmış" olarak hatırlanırken, tanıma belleği görevinde bu oran \%66'dır. Ancak çalışmanın detayları incelendiğinde, DRM listelerinin kritik çeldiricilere dair bellek yanılması oluşturma aralığının oldukça geniş olduğu görülmektedir. Araştırmacılar tarafından geliştirilen listeler arasında Pencere kritik çeldiricisi katılımcıların \%84’ü tarafından yanlışlıkla tanınırken, Kral kritik çeldiricisinin bellek yanılması oluşturma yüzdesi 27'dir. Stadler ve arkadaşları (1999) tarafından geliştirilen DRM listeleri çok sayıda bellek yanılması deneyinde kullanılmasına karşın gerçekte yalnızca ana dili İngilizce olan katılımcılarda uygulanmaya elverişlidir. Bu durum, bellek yanılması deneylerinin büyük ölçüde İngilizce ana dilli katılımcılarla yürütülmesine yol açmıştır. Bazı araştırmacılar Stadler ve arkadaşları (1999) tarafından geliştirilen listeleri kendi dillerine çevirerek kullanmışlardır (Örn., Anastasi, Rhodes, Marquez ve Velino, 2005, İspanyolca; Mısırlısoy, 2004, Türkçe; Stein ve Pergher, 2001, Portekizce; Zeelenberg ve Pecher, 2002, Flemenkçe) Ancak DRM etkisinin, liste sözcükleri arasındaki dile özgü anlamsal ilişkilere (semantic association) dayandığı düşünüldüğünde (Gallo, 2010), farklı dillerde geliştirilmiş olan listeleri yalnızca çevirerek kullanmak yeterli olmayabilir. Örneğin, Anastasi Rhodes, Marquez ve Velino (2005), DRM etkisi ve dil arasındaki ilişkiyi inceledikleri çalışmalarında, İngilizce'den çevrilerek kullanılan DRM listelerinin doğal anlamsal ilişkisinin bozulduğunu ve DRM etkisinin beklenenden daha düşük düzeyde olduğunu göstermişlerdir. Literatürdeki bu ihtiyaçtan yola çıkarak farklı ülkelerden araştırmacılar kendi dillerine uygun olarak çeşitli DRM listeleri geliştirmişlerdir (Örn., Anastasi, De Leon ve Rhodes, 2005, İspanyolca; Cadavid ve Beato, 2017, Ispanyolca; Göz, 2005, Türkçe; Iacullo ve Marucci, 2016, Italyanca; Johansson ve Stenberg, 2002, Isveççe; Stein, Feix ve Rohenkohl, 2006, Portekizce; Ulatowska ve Olszewska, 2013, Lehçe).

Farklı dillerde geliştirilen DRM listelerinin özellikleri incelendiğinde bazı ortak çıkarımlar yapmak mümkündür. İlk olarak, katılımcılar liste sözcükleri ve kritik DRM sözcükleri için söz konusu sözcükleri çalışma aşamasında görmüş olduklarına dair benzer seviyede olumlu tanıma kararı verirlerken, liste sözcükleriyle ilişkili olmayan çeldi- 
riciler (kritik olmayan çeldiriciler) için verilen olumlu tanıma kararları belirgin seviyede daha düşüktür. $\mathrm{Bu}$ durum başarılı bir şekilde DRM etkisinin ortaya çıktığını göstermektedir. Bununla birlikte tüm listelerin benzer seviyede bellek yanılmasına yol açmadığı, aynı çalışma içinde dahi DRM etki ranjının oldukça geniş olduğunu söylemek mümkündür (Örn., Anastasi, De Leon ve Rhodes, 2005; Cadavid ve Beato, 2017; Stein ve ark., 2006). Son olarak, geliştirilen listelerde bazı sözcük özellikleri (Örn., kullanım sıklığl, somutluk) kontrol edilmesine karşın, sözcüklerin sahip olduğu duygusal değerlik ve uyarılmış düzeyleri sıklıkla göz ardı edilmiştir.

Duygu ve bellek etkileşimini inceleyen araştırmalarda deneysel uyaranlar olarak sözcükler sıklıkla kullanılmaktadır ve bu çalışmalarda sözcüklerin sahip olduğu duygusal özelliklerin belleği farklı şekillerde etkilediği gösterilmiştir. Örneğin, nötr sözcüklere kıyasla duygu içerikli sözcükler için bellek doğruluğunun arttığı bilinmektedir (Bkz. Kensinger ve Schacter, 2008). Tanıma belleği görevi kullanılan çalışmalarda ise söz konusu farklılaşmanın katılımcıların tepki yanlılığı ile ilişkili olabileceği gösterilmiştir. Katılımcılarda negatif sözcükler için artan liberal tepki yanlılığı -sözcüklerin gerçekten eski olup olmamasından bağımsız olarak "eski" olarak rapor edilme eğilimi- sıklıkla gösterilen bir bulgudur (Dougal ve Rotello, 2007; Kapucu, Rotello, Ready ve Seidl, 2008; White, Kapucu, Bruno, Rotello ve Ratcliff, 2014; Thapar ve Rouder, 2009). Bellek yanılmaları bağlamında incelendiğinde ise duygunun değerlik ve uyarılmışlık boyutlarının katılımcılarda farklı düzeylerde bellek yanılmasına yol açtığı bulunmuştur. Örneğin, Norris, Leaf ve Fenn (2018) DRM paradigmasında pozitif ya da nötr sözcüklere kıyasla negatif liste sözcüklerinin hem hatıllanma doğruluğunun hem de negatif kritik çeldiricilere ilişkin bellek yanılmasının arttığını göstermişlerdir. Negatif sözcükler için artan DRM etkisi diğer araştırmacılar tarafından da desteklenmiştir (Dewhurst, Anderson ve Knott, 2012; Gong, Xiao ve Wang, 2016). Dahas1, tanıma belleği görevinin kullanıldığı bir çalışmada DRM etkisinin farklı değerlik düzeyindeki sözcüklere yönelik bellek doğruluğundaki farklılaşmadan değil negatif kritik çeldiricilere yönelik liberal tepki yanlılığındaki artıştan kaynaklanabileceği gösterilmiştir (Yüvrük, Kapucu ve Turan, 2018). Tüm bu bulgular, geliştirilen DRM listelerinin duygusal içeriklerine dikkat etmenin önemini vurgulamaktadır.

Stadler ve arkadaşlarının (1999) geliştirdikleri DRM listelerini duygusal içerikleri bakımından gruplamak mümkündür. Örneğin, öfke, örümcek, soğuk, hırsı, çöp gibi DRM listeleri negatif, müzik, uyku, meyve, tatl gibi DRM listeleri pozitif, pencere, 
araba, şehir, kalem gibi DRM listeleri ise nötr listeler olarak gruplandırılabilir ${ }^{1}$. Buna karşın araştırmacılar söz konusu listelerin duygusal içeriklerine yönelik herhangi bir çalışma gerçekleştirmemişlerdir. Farklı duygusal niteliğe sahip söz konusu DRM listeleri çeşitli ampirik çalışmalarda bir arada kullanılmıştır. Sözcüklerin duygusal niteliklerinin dengelenmemiş olduğu listelerin bir arada kullanılması, duygunun bellek yanılmaları üzerinde karıştırıcı (confounding) bir etki göstermesine neden olabilir. Ulaşılabilen sınırlı sayıda araştırmada DRM listelerinin duygusal içeriklerinin incelendiği görülmüştür. Stein ve arkadaşları (2006), Portekizce duygusal içerikli sözcüklerden oluşan sekiz DRM listesi geliştirmişlerdir. Aynı araştırmacılar, daha sonra anlamsal ilişkiler, somutluk, kullanım sıklı̆̆ı ve duygusal değerlik puanlarını içeren 44 sözcük listesi geliştirmiş olmalarına karşın bu kez söz konusu listelerin ne düzeyde bellek yanılmasına yol açtığını test etmemişlerdir (Stein ve Azevedo Gomes, 2009). Türkçe literatür incelendiğindeyse, farklı ampirik çalışmalarda DRM listelerinin kullanıldığı görülebilir (Göz, 2005; Göz, Karahan ve Tekcan, 2016; Misırlısoy, 2004; Şahin, 2011; Şahin ve Tekman, 2019). Ancak ulaşılabilen çalışmaların hiçbirinde dilimiz özelliklerine uygun, duygusal içerikli sözcüklerden oluşan DRM listelerinin geliştirilmediği görülmüştür. Bellek yanılmaları araştırmalarında duygu önemli bir değişken olmasına karşın hem Türkçe hem de uluslararası literatürde kullanılan DRM listelerinin duygusal özellikleri sıklıkla göz ardı edilmiştir. Literatürdeki bu eksikliklerden yola çıkarak, bu çalışmada, uyarılmışlık seviyeleri açısından dengelenmiş pozitif, negatif ve nötr duygu içerikli sözcüklerden oluşan Türkçe DRM listelerinin geliştirilmesi ve literatüre kazandırılması amaçlanmıştır.

Geliştirilen DRM listelerinin bellek yanılması oluşturma düzeyleri tanıma belleği görevi kullanılarak ölçülmüş; böylece serbest hatırlama görevlerine kıyasla bellek performansı daha kapsamlı bir şekilde değerlendirilebilmiştir. Katılımcıların sunulan liste sözcükleri için isabet oranları ve kritik çeldiriciler için yanlış alarm oranlarına ek olarak, DRM listeleriyle ilişkisiz kritik olmayan çeldiricilere ilişkin yanlış alarm oranları da ölçülmüştür. DRM etkisinin gözlenebilmesi için kritik çeldiriciler için “eski” tanıma kararı yüzdesinin çalışılan liste sözcükleriyle benzer seviyede, kritik olmayan çeldiricilerden ise anlamlı seviyede yüksek olması beklenmiş ve söz konusu yüzdelerin literatürdeki çalışmalarla benzer düzeyde olacağı öngörülmüştür.

1 Bu gruplama Kapucu ve arkadaşlarının (2018) Türkçe sözcükler için değerlik norm değerlerinden hareketle yapılmıştır. 


\section{YÖNTEM}

\section{Katılımcilar}

Ülkemizdeki bir devlet üniversitesinin psikoloji bölümünden 92 öğrenci (\%79’u kadın) çalışmaya gönüllü olarak katılmıştır. Yaş ortalamasının 21.14 olduğu örneklemde $(S S=1.83)$, duygu (pozitif, negatif, nötr) ve sözcük türü (eski, kritik çeldirici, kritik olmayan çeldirici) denek-içi değişkenlerdir. Tüm katılımcılar her üç duygusal içerikli sözcüklerden oluşan DRM listelerini çalışmışlar, ardından bu sözcüklere ilişkin bir tanıma belleği görevini tamamlamışlardır.

\section{Veri Toplama Araçları}

DRM listelerinin oluşturulması. Bu çalışma kapsamında her duygu grubundan (pozitif, negatif, nötr) 10'ar adet olmak üzere toplamda 30 DRM listesi oluşturulmuştur. Her bir DRM listesi 10 çağrışım sözcüğünden oluşmaktadır (benzer liste uzunluğu için bkz. Norris ve ark., 2018). Çalışmada kullanılan tüm sözcük listeleri Ek 1'de verilmiştir. Bu listelerin oluşturulmasında belirlenen seçme kriterleri ve izlenen işlem basamakları şu şekildedir:

Kritik çeldiricilerin belirlenmesi. Kritik çeldiriciler, çalışma aşamasında katılımcılara sunulmayan, DRM listesinin ortak olarak çağrıştırdığı, listenin ana temasını oluşturan sözcüklerdir. Kritik çeldiricilerin belli sözcük özellikleri açısından birbirine benzer nitelikte olması hedeflenmiştir. Bu amaçla sözcüklerin somutluk, sıklık, çağrışım seti genişliği ve imgelem gücü değerleri Tekcan ve Göz (2005)'ün çalışmasından elde edilmiştir. Somut$l u k$, sözcüğün ne derece duyu organlarıyla algılanabilen bir sözcük olduğuna, sıklık, sözcüğün yazılı Türkçe'de bir milyon sözcük içinde ne sıklıkta kullanıldığına, çağrışım seti genişliği, sözcüğün toplam kaç farklı sözcüğü çağrıştırdığına, imgelem gücü ise sözcüklerin zihinsel imge uyandırma ya da hayal edilebilme gücüne işaret etmektedir. Çalışmada kullanılan sözcüklerin değerlik ve uyarılmışlık puanları ise Kapucu ve arkadaşlarının (2018) norm çalışmasından elde edilmiştir. Değerlik, bir sözcüğün ne kadar olumlu/hoş ya da olumsuz/nahoş bir sözcük olduğunu, uyarılmışlık ise sözcüğün ne kadar sakinlik ya da heyecan uyandırdığını ifade etmektedir. Kapucu ve arkadaşlarının (2018) çalışmasında sözcüklerin norm değerleri 9'lu Likert tipi maddeler üzerinden belirlenmiştir. " 1 " puan sözcüğün olumsuz ya da sakinlik uyandıran bir sözcük olduğuna işaret ederken, "9" puan olumlu ya da heyecan uyandıran bir sözcük olduğuna işaret etmektedir.

Kritik çeldiricilerin tüm sözcük özelliklerine dair norm değerlerini elde edebilmek için söz konusu iki norm çalışmasındaki ortak sözcükler belirlenmiştir. Belirlenen 564 
ortak sözcükten her duygu koşulu için en az 20'şer adet aday kritik çeldirici şu kriterlere uygun olarak seçilmiştir: Kapucu ve arkadaşlarının (2018) norm değerlerinden hareketle değerlik puanının 7'den yüksek olduğu sözcükler pozitif, 3’ten düşük olduğu sözcükler negatif ve 5'e yakın olduğu sözcükler nötr aday kritik çeldiriciler olarak sınıflandırılmıştır. Uyarılmışlık düzeylerinin dengelenebilmesi için tüm duygu koşullarındaki aday kritik çeldiricilerin uyarılmışlık puanlarının 6’ya yakın olmasına dikkat edilmiştir. Ek olarak yeterli uzunlukta DRM listeleri geliştirebilmek için Tekcan ve Göz’ün (2005) verilerinden hareketle yalnızca çağrışım seti genişliğinin 10'dan yüksek olduğu sözcükler aday kritik çeldirici havuzuna alınmıştır. Seçim yapılırken diğer sözcük özelliklerinin duygu koşulları arasında birbirine yakın olmasına özen gösterilmiştir. Norm değerlerine ek olarak birbiriyle semantik olarak fazlaca ilişkili olan kritik çeldiricilerden (örneğin; ölüm, mezar ve cenaze) yalnızca biri seçilmiş, böylece kritik çeldiricilerin de kendi içinde semantik kategori oluşturması engellenmeye çalışılmıştır. Daha sonra aday havuzu daraltılarak, her duygu koşulundan bu kriterleri en iyi sağlayan 10 kritik çeldirici belirlenmiştir. $\mathrm{Bu}$ kriterlere göre belirlenen kritik çeldiricilerin duygu puanı ortalamalarının duygu koşuluna göre istenen yönde birbirinden farklılaşıp farklılaşmadığı gerçekleştirilen tek yönlü varyans analiziyle incelenmiştir. Tüm sözcük özelliklerine dair elde edilen ortalamalar Tablo 1'de verilmiştir. Buna göre, değerlik $\left(F(2,29)=452.94, p<.001, \eta^{2}=.97\right)$ ve uyarılmışlık $\left(F(2,29)=102.51, p<.001, \eta^{2}=.88\right)$ puanlarının duygu koşulları arasında istenen yönde birbirinden farklılaştığ 1 görülmüştür. Bonferroni düzeltmesi yapılan ikili karşılaştırmalar pozitif kritik çeldiricilerin en yüksek değerliğe, negatif kritik çeldiricilerinse en düşük değerliğe sahip olduğunu, nötr kritik çeldiricilerin değerliğinin her ikisinin ortasında ve her ikisinden anlamlı olarak farklılaştığını göstermiştir (tüm p'ler < .001). Uyarılmışlık puanları incelendiğinde, nötr kritik çeldiricilerin en düşük uyarılmışlik seviyesinde olduğu $(p<.001)$, ancak pozitif ve negatif çeldiricilerin birbirinden farklılaşmadığ 1 görülmektedir $(p=.25)$. Bu bulgular, geliştirilen listelerin kritik çeldiricilerinin istenen değerlik ve uyarılmışlık düzeylerine sahip olduğunu ortaya koymuştur. Bir sonraki aşamada, her bir kritik çeldiriciye ait DRM liste sözcükleri belirlenmiştir.

Tablo 1. Kritik çeldiricilerin duygu koşuluna göre sözcük özellikleri ortalama ve standart sapma değerleri.

\begin{tabular}{lcccccc}
\hline \multirow{2}{*}{ Duygu } & İmgelem & Somutluk & $\begin{array}{c}\text { Çă̆rışım Seti } \\
\text { Genişliği }\end{array}$ & Sıklık & Değerlik & Uyarılmışlık \\
\cline { 2 - 7 } & Ort. $($ SS $)$ & Ort. $($ SS $)$ & Ort. $($ SS $)$ & Ort. $($ SS $)$ & Ort. $($ SS) & Ort. (SS) \\
\hline Pozitif & $5.05(0.99)$ & $4.33(1.58)$ & $13.60(2.71)$ & $283.30(270.91)$ & $7.76(0.28)$ & $6.55(0.20)$ \\
Negatif & $4.17(1.03)$ & $4.07(1.76)$ & $14.50(2.22)$ & $78.60(37.97)$ & $2.05(0.47)$ & $6.27(0.36)$ \\
Nötr & $4.97(1.66)$ & $5.31(2.12)$ & $17.60(2.12)$ & $181.40(130.40)$ & $5.04(0.49)$ & $4.49(0.43)$ \\
\hline
\end{tabular}


Çağrışım listelerinin oluşturulması. Kritik çeldiricilere ait çağrışım listelerinin oluşturulmasında Tekcan ve Göz'ün (2005) çağrışım listelerinden yararlanılmış, ilk olarak kritik çeldiricilere ait mevcut çağrışım listeleri belirlenmiştir. Söz konusu çağrışım listeleri içerisinde, kritik çeldiricilerden herhangi biriyle aynı olan liste sözcükleri çağrışım listelerinden çıkarılmıştır. Aynı zamanda çağrışım listeleri arasında birden fazla kez tekrar eden sözcükler de tespit edilmiş, bu sözcüklerin yalnızca çağrışım gücünün en yüksek olduğu DRM listesinde yer almasına, diğer DRM listelerinden silinmesine karar verilmiştir. Çağrışım güçlerinin DRM listeleri arasında benzer olduğu durumlarda ise çağrışım setlerinin genişliği gözetilerek karar verilmiştir. Örneğin, kardeş kelimesi hem aile hem de arkadaş kritik çeldiricilerinin çağrışım listelerinde yer almaktadır ve her iki listedeki çağrışım gücü de 4'tür. Ancak aile sözcüğün çağrışım seti genişliği daha fazla olduğu için, kardeş sözcüğünün yalnızca arkadaş listesinde kullanılmasına karar verilmiş, aile listesinden çıkarılmıştır. Tüm eleme işlemleri sonucunda bir sözcüğün yalnızca bir DRM listesinde yer aldığ1 10'ar sözcükten oluşan DRM listeleri geliştirilmiştir.

Kritik olmayan çeldiricilerin belirlenmesi. Kritik olmayan çeldiriciler tanıma belleği görevinin test aşamasında yeni sözcükler olarak sunulmak üzere seçilmiş, çalışılan DRM liste sözcükleri ile ilişkisiz çeldiricilerdir. Söz konusu çeldiriciler, Tekcan ve Göz (2005) ile Kapucu ve arkadaşlarının (2018) norm çalışmalarındaki ortak sözcükler arasından, kritik çeldiricilerin seçiminde kullanılan aynı kriterlere uygun olarak seçilmişlerdir. Öncelikle her duygu koşulundan 3'er adet kritik olmayan çeldirici belirlenmiş, ardından Tekcan ve Göz'ün (2005) çağrışım normları kullanılarak her bir kritik olmayan çeldiriciye ilişkin 2 adet sözcük daha eklenmiştir. Böylece test aşamasında sunulmak üzere her duygu koşulunda 3'er adet 3'er sözcük içeren kritik olmayan çeldirici listeleri oluşturulmuştur. Çalışmada kullanılan tüm kritik olmayan çeldiriciler Ek 1'de verilmiştir.

\section{İşlem}

Ülkemizdeki bir devlet üniversitesinin Bilimsel Araştırmalar ve Yayın Etiği Kurulu'ndan araştırma izninin alınmasının ardından veri toplama süreci başlatılmış, onam formunu dolduran katılımcılar bireysel olarak deneye alınmıştır. Deneyde uyaran sunumu ve katılımcıların tanıma kararı kayıtları E-Prime 2 (Schneider, Eschman ve Zuccolotto, 2012) paket programıyla sağlanmıştır. Katılımcıların tanıma kararını ne zaman verdiğine ilişkin tepki zamanı kaydı alınmamıştır. 
Her bir deney, çalışma ve test aşaması olmak üzere iki aşamadan oluşmaktadır ve yaklaşık 25 dk. sürmektedir. Katılımcılar bir bellek deneyine katılacakları konusunda bilgilendirilmiş, çalışma aşamasında gördükleri sözcükleri mümkün olduğunca iyi bir şekilde öğrenmeleri istenmiştir. DRM listelerinin doğasına ilişkin ise herhangi bir bilgilendirme yapılmamıştır. Bilişsel yükün aşırı artışını engellemek için çalışma aşamasında katılımcılar tüm DRM listelerini değil, her duygu koşulundan seçkisiz olarak belirlenen 5'er adet DRM listesini çalışmışlardır. Bu aşamada sunulan 15 liste, duygu gruplarına göre bloklar halinde ve blokların sırası dengelenmiş şekilde sunulmuştur. Bir duygu bloğu içerisinde hangi DRM listesinin sunulacağ 1 ise seçkisiz olarak belirlenmiştir. DRM listelerine ait sözcükler, literatürdeki çalışmalara benzer şekilde listenin kritik çeldiricisiyle çağrışım gücü yüksekten düşüğe olacak şekilde (Örn., Johannson ve Stenberg, 2002; Roediger ve McDermott, 1995; Stadler ve ark., 1999) 1500 ms süreyle ve 750 ms uyaranlar arası aralıkla sunulmuştur. Her bir liste sonunda diğer listeye geçmek için katılımcılara "Hazırsanız diğer listeye geçebilirsiniz" şeklinde bir uyarı verilmiş, katılımcılar hazır olduklarında "Boşluk" tuşuna basarak bir sonraki listeyi çalışmışlardır. Tüm listelerin çalışılmasının ardından test aşamasına geçilmiştir.

Test aşamasında katılımcılardan 45'i çalışma aşamasında sunulmuş (eski sözcükler) ve 42'si sunulmamış (yeni sözcükler) toplam 87 sözcük için tanıma kararı vermesi istenmiştir. Eski sözcükler, DRM listelerinde yer alan 2'nci, 5'inci ve 8 'inci s1radaki liste sözcükleridir. Eski sözcüklerin, DRM listelerinin başından, ortasından ve sonundan seçilmesine literatürdeki mevcut çalışmalardan (Bkz. Johannson ve Stenberg, 2002; Stadler ve ark., 1999; Stein ve ark., 2006) hareketle karar verilmiştir. Yeni sözcüklerin ise $15^{\prime}$ 'ini kritik çeldiriciler, 27'sini ise kritik olmayan çeldiriciler oluşturmaktadır. Daha önce bahsedildiği gibi kritik çeldiriciler çalışılan DRM listelerinin ana temasını oluşturan sözcüklerken, kritik olmayan çeldiriciler ise DRM listeleriyle ilişkisiz çalışma aşamasında sunulmamış yeni sözcüklerdir. Test aşamasında her bir sözcük ekranda 1500 sn. süre ile seçkisiz sırada sunulmuştur. Her bir test sözcüğünün ardından katılımcılardan 6’l1 güven değerlendirmesi kullanarak (“ 1 : Eminim yeni - 6 : Eminim eski”) ekranda gördükleri sözcüğün çalışma aşamasında sunulup sunulmadığını tespit etmeleri istenmiştir. Test aşamasının tamamlanmasının ardından katılımcıların geri bildirimleri alınmış, kendilerine teşekkür edilmiş ve oturum sonlandırılmıştır. 


\section{BULGULAR}

Verilerin analizinden önce, tanıma aşamasında katılımcıların verdikleri 1'den ("Eminim yeni") 3'e ("Yeni olabilir") olan güven değerlendirmeleri "yeni", 4'ten ("Eski olabilir") 6’ya ("Eminim eski”) olan güven değerlendirmeleriyse "eski” tepkisi olarak yeniden kodlanmış ve böylece tanıma kararları dikotomik hale getirilmiştir².

İlk olarak, genel bellek performanslarının değerlendirilmesi amacıyla katılımcıların “eski” tepki yüzdelerinin duygu grubu (pozitif, negatif ve nötr) ve sözcük türüne (eski, kritik çeldirici ve kritik olmayan çeldirici) göre farklılaşıp farklılaşmadığ1 3x3 tekrarlı ölçümler için iki yönlü varyans analiziyle test edilmiştir. Böylece katılımcıların isabet oranı (hit rate, eski sözcükler için “eski” tepki yüzdeleri) ve yanlış alarm oranlar1 ${ }^{3}$ (false alarm rate, yeni sözcükler için "eski” tepki yüzdeleri) aynı analize dahil edilmiştir. Söz konusu analizde eski kelimeler için isabet oranı genel bellek performansının, kritik ve kritik olmayan çeldiriciler için yanlış alarm oranları ise katılımcılarda ne düzeyde bellek yanılması oluşturulabildiğinin bir ölçütü olarak değerlendirilmiştir.

Her bir DRM listesinin katılımcıların yüzde kaçında bellek yanılması oluşturabildiği ise DRM listelerinin etkililiği olarak değerlendirilmiştir. Bunun için her bir test sözcüğüne o sözcüğü değerlendiren kişilerin yüzde kaçı tarafından "eski” tepkisi verildiği hesaplanmıştır. Bu aşamada sözcüklerden elde edilen veriler analize dahil edilmiştir. $\mathrm{Bu}$ sebeple sözcüklerin ait olduğu duygu grubu (pozitif, negatif ve nötr) ve türü (eski, kritik çeldirici ve kritik olmayan çeldirici) denekler arası değişken olarak ele alınmıştır. Hesaplanan "eski" tepki yüzdelerinin duygu ve sözcük türüne göre farklılaşıp farklılaşmadığı 3x3 denekler arası iki yönlü varyans analiziyle test edilmiştir. Gerçekleştirilen tüm analizlerde anlamlı temel etki ve etkileşimler için Bonferroni düzeltmesi uygulanan ikili karşılaştırmalar rapor edilmiştir.

2 Güven değerlendirmeleri bu çalışmayla bağlantılı başka bir ampirik çalışma (Yüvrük ve ark., 2018) kapsamında sinyal tespit analizlerini gerçekleştirmek için alınmıştır. Ancak sinyal tespit analizleri bu çalışmanın kapsamı dışında kalmaktadır. Ek olarak literatürdeki mevcut liste geliştirme çalışmalarında tanıma kararları sıklıkla dikotomik olarak ele alındığı için (Örn., Cadavid ve Beato, 2017; Stadler ve ark., 1999; Ulatowska ve Olszewska, 2013) bulguların karşılaştırılabilir olması adına katılımcıların tanıma kararları dikotomik hale getirilmiştir.

3 İşlem bölümünde de belirtildiği üzere yeni sözcükler, kritik çeldiriciler ve kritik olmayan çeldiricilerden oluşmaktadır. Gerçekleştirilen varyans analizinde her iki tür çeldirici için yanlış alarm oranları ayrı ayrı hesaplanmıştır. 


\section{Genel Bellek Performansları - İsabet ve Yanlış Alarm Oranları}

Katılımcıların isabet ve yanlış alarm oranlarına yönelik analizler, duygu $(F(2,182)$ $\left.=9.57, p<.001, \eta^{2}=.09\right)$ ve sözcük türü $\left(F(2,182)=510.12, p<.001, \eta^{2}=.85\right)$ temel etkilerinin istatistiksel olarak anlamlı olduğunu göstermiştir. Buna göre, nötr sözcüklere $($ Ort. $=.49, S S=.13)$, pozitif $($ Ort. $=.53, S S=.13)$ ve negatif $($ Ort. $=.55, S S=$ .13) sözcüklerden daha düşük oranda "eski" tepkisi verildiği (nötr-pozitif $p=.02$, nötr-negatif $p<.001$ ) ancak pozitif ve negatif sözcükler için farkın istatistiksel olarak anlamlı olmadığı görülmüştür $(p=.32)$. Sözcük türü temel etkisi incelendiğindeyse, katılımcıların isabet oranları ortalamasının $($ Ort. $=.77, S S=.10)$, yanlış alarm oranları ortalamalarından (kritik ve kritik olmayan çeldiriciler için) daha yüksek olduğu görülmüştür (tüm p'ler < .001). Yani katılımcılar öğrenme aşamasında çalıştıkları eski liste sözcüklerini yeni sözcüklerden daha yüksek oranda gördüklerini belirtmişlerdir. Daha önemlisi kritik çeldiricilerin yanlış alarm oranları (Ort. $=.61, S S=.19)$, kritik olmayan çeldiricilerin yanlış alarm oranlarından $($ Ort. $=.20, S S=.13)$ anlamlı olarak daha yüksek bulunmuştur $(p<.001)$. Katılımcılar öğrenme aşamasında her iki tür çeldiriciyi de hiç görmemiş olmalarına rağmen, kritik çeldiriciler için belirgin şekilde daha yüksek oranda "eski” tepkisi vermişlerdir. Bu bulgu katılımcılarda DRM paradigması aracılığıyla başarılı bir şekilde bellek yanılması oluşturulabildiğini göstermektedir. Ek olarak, gerçekleştirilen analizler duygu ve sözcük türü etkileşiminin de anlamlı olduğunu ortaya koymuştur, $F(4,364)=9.85, p<.001, \eta^{2}=.10$. Etkileşimin kaynağını anlamak üzere gerçekleştirilen ikili karşılaştırmalar (Bkz. Şekil 1), yalnızca kritik olmayan çeldiricilere yönelik yanlış alarm oranlarında duygu koşulları arasında farkl1laşma olduğunu göstermiştir. Kritik olmayan negatif çeldiriciler (Ort. $=.29, S S=.20)$ için yanlış alarm oranları, kritik olmayan pozitif $($ Ort. $=.16, S S=.17)$ ve nötr $($ Ort. $=$ $.15, S S=.16$ ) çeldiricilerin yanlış alarm oranlarından daha yüksektir (tüm $p$ 'ler < $.001)$. Yine de bu oran, negatif sözcükler için isabet oranları (Ort. $=.77, S S=.15)$ ya da negatif kritik çeldiriciler için yanlış alarm oranlarından (Ort. $=.60, S S=.22)$ anlamlı olarak daha düşüktür (tüm p’ler <.001). Ek olarak, isabet oranları ve kritik çeldiricilerin yanlış alarm oranları duygudan farklı şekillerde etkilenmemiştir (tüm p'ler $>$.05). Sonuç olarak bulgular, tüm duygu koşullarında isabet oranları açısından benzer bellek performanslarının gözlendiğini ve başarılı bir şekilde bellek yanılması oluşturulabildiğini desteklemektedir. Bir sonraki aşamada, her bir DRM listesinin ne düzeyde bellek yanılması oluşturduğu incelenmiştir. 


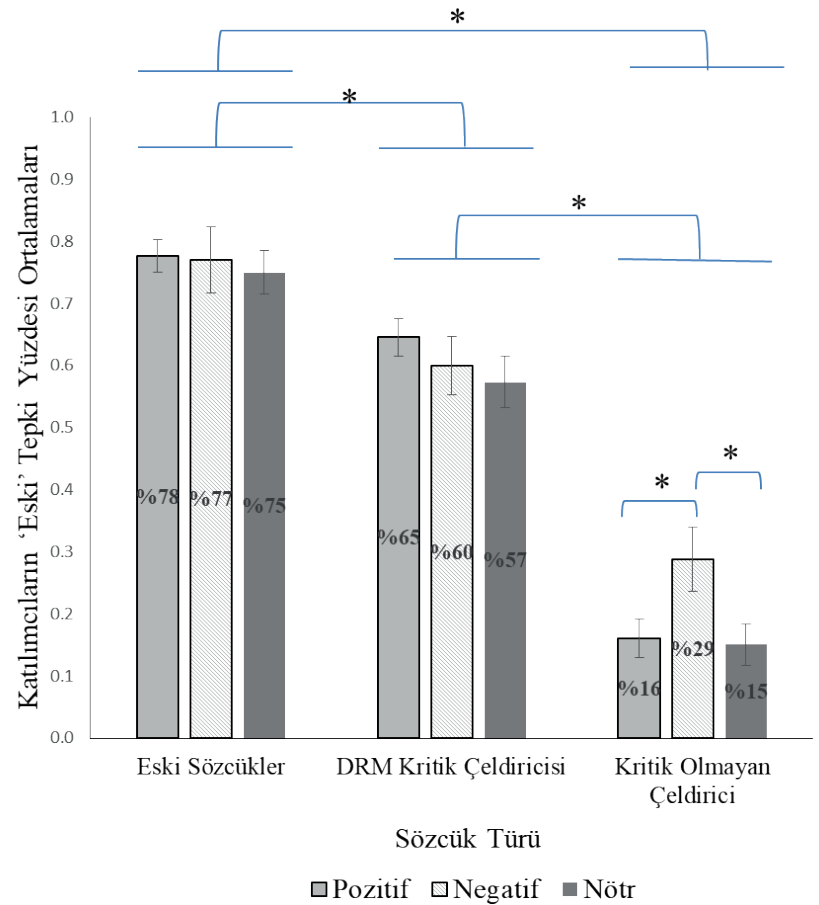

Şekil 1. Katılımcıların duygu ve kelime türüne göre "eski” tepki ortalamaları.

Not: Eski sözcükler için "eski” tepki yüzleri isabet oranlarını, kritik ve kritik olmayan çeldiriciler için "eski" tepki yüzdeleri yanlış alarm oranlarını vermektedir. $* p<.001$.

\section{DRM Listelerinin Etkililiği}

Test sözcükleri bazında "eski" tepki oranları ${ }^{4}$ incelendiğindeyse, duygu $(F(2,138)=$ $\left.3.73, p=.03, \eta^{2}=.05\right)$ ve sözcük türü $\left(F(2,138)=204.09, p<.001, \eta^{2}=.74\right)$ temel etkilerinin anlamlı olduğu görülmüştür. Buna göre negatif sözcüklere "eski" tepkisi veren katılımcıların yüzdesi (Ort. $=.66, S S=.24)$, nötr sözcüklere "eski" tepkisi veren kat1lımcıların yüzdesinden (Ort. $=.60, S S=.25)$ daha yüksektir $(p=.02)$. Yani, negatif sözcükler sözcük türünden bağımsız olarak katılımcılarda "eski" deme eğilimini artırmış görünmektedir. Buna karşın pozitif sözcüklere verilen "eski" tepki yüzdesi (Ort. = $.63, S S=.26$ ) diğer duygu koşullarından anlamlı olarak farklılaşmamaktadır (tüm $p$ 'ler $>$.05). Sözcük türü temel etkisi incelendiğindeyse tüm sözcük türlerindeki "eski” tepki yüzdelerinin birbirinden anlamlı olarak farklılaştığı görülmüş̧ür (tüm $p^{\prime} l e r<.001$ ). Beklenen şekilde katılımcılar arasında en yüksek oranda eski liste kelimeleri için (Ort. $=.77, S S=.11)$, en düşük ise kritik olmayan çeldiriciler için $($ Ort. $=.20, S S=.13)$ "eski"

4 Her bir test sözcüğüne katılımcıların yüzde kaçının “eski” tepkisi verdiği. 
tepkisi verilmiştir. Kritik çeldiriciler için ortalama \%63 oranında $(S S=.17)$ "eski” tepkisi verilmiş olup, bu değer DRM listelerinin etkililiğini göstermektedir. Son olarak etkileşim etkisinin $(F(4,138)=1.27, p=.29)$ istatistiksel açıdan anlamsız olması her üç duygu koşulunda geliştirilen DRM listelerin benzer etki düzeylerine sahip olduğunu göstermektedir.

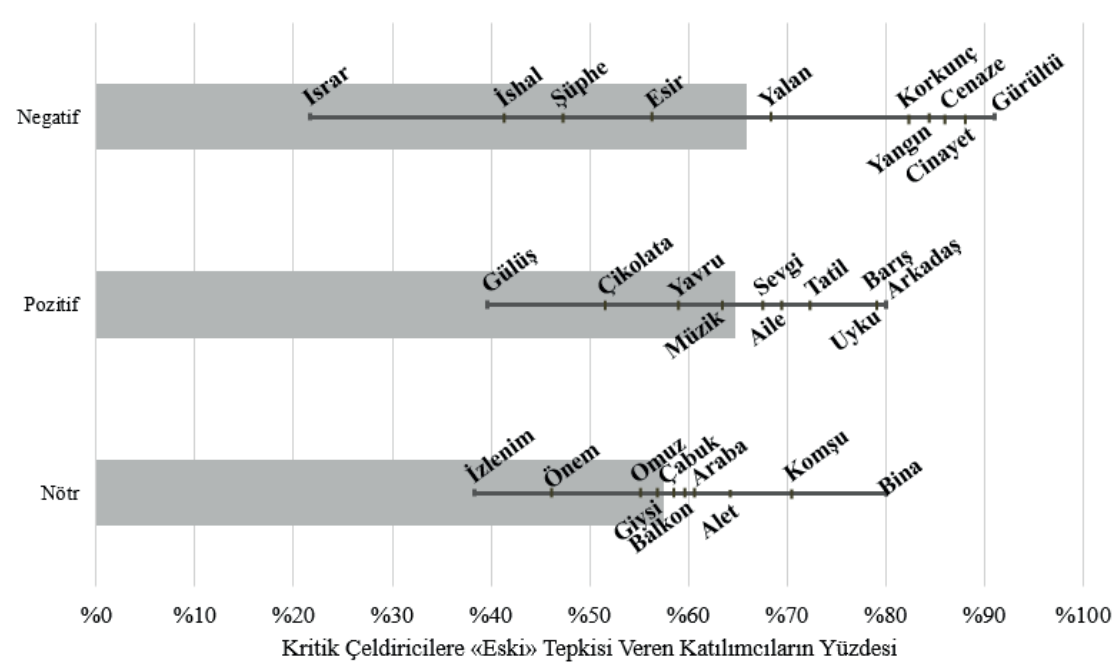

Şekil 2. Duygu koşullarına göre DRM listelerinin etkililiği.

Not: Gri çubuk grafikler ortalama değerleri vermektedir. Şekil üzerindeki sözcükler, her bir kritik çeldiricinin katılımcıların yüzde kaçı tarafından "eski" olarak nitelendirildiğine göre konumlandırılmıştır.

Geliştirilen DRM listelerinin etkililiği daha detaylı incelendiğinde (Bkz. Şekil 2) ise DRM listelerinin bellek yanılması oluşturmada geniş bir ranja sahip olduğu görülmüştür. Nötr listeler için bu ranj \%42 olup, en düşük DRM etkisine sahip İzlenim listesinin katılımcılarda \%38 oranında bellek yanılması oluşturduğu, en yüksek DRM etkisine sahip Bina listesinin ise \%80 oranında bellek yanılması oluşturduğu gözlenmiştir. Pozitif DRM listeleri de nötr listelere oldukça benzer etki göstermişlerdir. Pozitif listeler için etki ranj1 \%40 olup, en düşük DRM etkisine sahip Gülüş listesi \%40 oranında, en yüksek DRM etkisine sahip Arkadaş listesi \%80 oranında bellek yanılması oluşturmuştur. Negatif DRM listeleri için etki ranjının daha geniş olduğu (\%69) olduğu tespit edilmiştir. Israr listesi \%22 oranıyla en düşük DRM etkisine sahipken, Gürültü listesi \%91 oranıyla bu çalışmada en yüksek bellek yanılmasını oluşturan listedir. 


\section{TARTIŞMA}

Bu çalışmada, Türkçe literatürde ilk kez, duygusal içerikli sözcüklerden oluşan Türkçe DRM listeleri geliştirilmiş ve bu listelerin bellek yanılması oluşturma etkililikleri test edilmiştir. Tekcan ve Göz’ün (2005) somutluk, sıklık, imgelem gücü ve çağrışım seti norm değerlerinden ve Kapucu ve arkadaşlarının (2018) değerlik ve uyarılmışlık norm değerlerinden hareketle her duygu koşulundan (pozitif, negatif ve nötr) 10'ar adet DRM listesi oluşturulmuştur. Tanıma belleği görevinden elde edilen bulgular katılımcılarda kritik çeldiricilere yönelik bellek yanılmasının başarılı bir şekilde oluşturulabildiğini göstermiştir. DRM listelerinin etkililikleri özgül olarak değerlendirildiğinde negatif listelerin katılımc1larda ortalama \%66, pozitif listelerin \%65 ve nötr listelerin \%58 oranında bellek yanılmas1na yol açtığı gözlenmiştir. Uluslararası literatür incelendiğinde, elde edilen bulguların literatürdeki mevcut liste geliştirme çalışmalarıyla uyumlu olduğu görülmüştür. Örneğin, tanıma belleği görevinde Stadler ve arkadaşları (1999) katılımcılarda \%66, Anastasi, De Leon ve Rhodes (2005) \%68, Ulatowska ve Olszewska (2013) \%57 oranında bellek yanılması oluşturabilmişlerdir. Bununla birlikte bazı çalışmalarda katılımcıların isabet oranlarının, kritik çeldiriciler için yanlış alarm oranlarından farklılaşmadığı bulunmuştur (Örn., Roediger ve McDermott, 1995; Stadler ve ark., 1999). Bu çalışmada hem genel bellek performansına ilişkin analizlerde hem de DRM listelerinin özgül etkililiklerine dair analizlerde eski liste sözcüklerine kritik çeldiricilerden daha yüksek oranda “evet” tepkisi verildiği görülmüştür. Çalışmalar arasındaki duyusal modalite farkının söz konusu farklılaşmayı açıklayabileceği düşünülmüştür. Literatürde işitsel sunumun görsel sunuma kıyasla DRM paradigmasında daha yüksek seviyede bellek yanılmasına yol açtığını gösteren çalışmalar bulunmaktadır (Cleary ve Greene, 2002; Gallo, McDermott, Percer ve Roediger, 2001; Smith ve Hunt, 1998; aksi yönde bulgular için bkz. Maylor ve Mo, 1999; Pierce, Gallo, Weiss ve Schachter, 2005). Dahası Cleary ve Greene (2002) DRM paradigmasında işitsel sunumun görsel sunuma kıyasla sunulmayan kritik çeldiriciler için daha yüksek oranda yanlış alarma yol açarken, sunulan liste sözcükleri için daha düşük oranda isabet oranına yol açtığını göstermişlerdir. $\mathrm{Bu}$ çalışmada sözcükler görsel olarak sunulurken, bazı çalışmalarda işitsel sunum gerçekleştirilmektedir. Literatürdeki bulgulardan hareketle görsel sunumun, eski liste sözcükleri için bellek performansını artıran bir faktör olabileceği düşünülmüştür (Bkz. Anastasi, De Leon ve Rhodes, 2005; Ulatowska ve Olszewska; 2013). Yine de bu çalışmada DRM etki düzeylerinin literatürle uyumlu olması, çalışmanın ana amacı olan bellek yanılmalarının başarılı bir şekilde ortaya çıkartılabildiğini desteklemektedir. 
DRM listelerinin özgün etkililiklerine dair analizlerde duygu ve sözcük tipi etkileşimi olmaması her üç duygu koşulunda benzer seviyelerde bellek yanılması oluşturulabildiğini göstermiştir. Bununla birlikte duygu temel etkisi incelediğinde, sözcük türünden bağımsız olarak negatif sözcükler için daha yüksek oranda "evet" tepkisi verildiği görülmüştür. Genel bellek performansına ilişkin analizler de bunu desteklemiş, katılımcıların kritik olmayan negatif çeldiriciler için daha yüksek oranda yanlış alarm tepkisi verdiği tespit edilmiştir. Literatürdeki duygu ve bellek etkileşimine ilişkin çalışmalar, bu çalışmada gözlenen negatif sözcüklerde artan "evet” deme eğiliminin liberal tepki yanlılığ 1 ile ilişkili olabileceğini düşündürmektedir (Dougal ve Rotello, 2007; Kapucu ve ark., 2008). Bu çalışmada, katılımcıların tepki yanlılığına ilişkin doğrudan bir ölçüm alınmasa da literatürdeki bulgular bu yorumu desteklemektedir. Örneğin, Yüvrük ve arkadaşları (2018) tarafından yakın zamanda gerçekleştirilen bir çalışmada, kritik çeldiricilerin eski liste sözcüklerinden ayırt edilmesine ilişkin bellek doğruluğunun duygudan etkilenmediği gösterilmiştir. Katılımcılar, pozitif ya da nötr kritik çeldiricilere kıyasla, negatif kritik çeldiriciler için liberal bir tepki yanlılı̆̆ benimsemişlerdir. Bu bulgular, gelecek çalışmalarda duygu-bellek yanılması ilişkisinde katılımcıların tepki yanlılıklarının göz önüne alınması gereken önemli bir değişken olduğunu göstermiştir.

Bu çalışmada geliştirilen DRM listelerinin bellek yanılması oluşturma düzeyleri yalnızca tanıma belleği göreviyle test edilmiştir. Daha önce bahsedildiği üzere, tanıma belleği görevi, katılımcıların bellek performansına ilişkin daha kapsamlı bir değerlendirme yapma imkânı sağlamıştır. İsabet ve yanlış alarm oranlarının birlikte değerlendirilmesinin, özellikle duygu ve bellek literatüründe önemli bir araştırma konusu olan tepki yanlılığının (Örn., Dougal ve Rotello, 2007) bellek yanılmaları bağlamında da çalışılmasına katkı sağlayabileceği düşünülmüştür. Bununla birlikte literatürde bellek yanılmalarının serbest hatırlama görevleriyle de incelendiği çok sayıda çalışma mevcuttur (Örn., Dewhurst ve ark., 2012; Johansson ve Stenberg, 2002; Stadler ve ark., 1999). Bu çalışmalarda genel olarak katılımcılardan her bir DRM listesinin sonunda serbest hatırlama görevini tamamlamaları istenmektedir. Elde edilen ortak bulguya göre kritik çeldiricilerin hatırlanma oranı, çalışılan DRM listelerinin ortasındaki sözcüklerin hatırlanma oranıyla benzer seviyededir (Örn., Roediger ve McDermott, 1995; Stadler ve ark., 1999). Geliştirilen listelerin bellek yanılmasını serbest hatırlama göreviyle incelemek isteyen araştırmacıların da kullanımına sunulabilmesi için gelecek çalışmalarda mevcut listeler ser- 
best hatırlama göreviyle de test edilebilir. Böylece, listelerin bellek yanılması oluşturma düzeylerine ilişkin bu çalışmada elde edilen kanıtlar güçlendirebilir.

Bu çalışma, literatüre birkaç açıdan özgün katkı sağlamaktadır. İlk olarak, geliştirilen DRM listeleri çeviri değildir ve dilimiz sözcük özelliklerine uygun olarak geliştirilmiştir. Bu açıdan liste sözcükleri arasındaki anlamsal bağlantı ve çağrışımlar bozulmadan bellek yanılması oluşturulabilmiştir. Böylece gelecekte Türkçe ana dilli örneklemlerde gerçekleştirilecek bellek yanılması çalışmalarının kullanımına sunulmuştur. İkinci ve daha önemlisi ise, sözcüklerin değerlik ve uyarılmışlık puanlarının incelenmesiyle hem ulusal hem de uluslararası literatüre önemli bir katkı sağlanabileceği düşünülmüştür. Duygu, bellek yanılması literatüründe önemli bir değişken olmasına karşın, duygu içerikli sözcüklerden oluşan liste geliştirme çalışmaları ihmal edilmektedir. Oldukça sınırlı sayıda araştırmada kelimelerin yalnızca değerlik düzeyleri ele alınmış, uyarılmışlık düzeyleri neredeyse hiç incelenmemiştir (Örn., Stein ve ark., 2006). Ulaşılabilen çalışmaların yalnızca birinde hem değerlik hem uyarılmışlık puanları verilmiştir (Stein ve Azevedo Gomes, 2009). Bu çalışmada geliştirilen DRM listelerinin uyarılmışlık düzeyleri dengelenmiş, yalnızca değerlik düzeyleri açısından farklılaşan listeler geliştirilmiştir. Böylece, çalışmada geliştiren duygusal DRM listelerinin, başta bilişsel psikoloji olmak üzere psikolojinin farklı alanlarında duygu ve bellek yanılmasını inceleyen araştırmacılara fayda sağlayacağı düşünülmektedir.

Finansal Destek: Yazarlar bu çalışma için finansal destek almamışlardır.

\section{Kaynakça}

Anastasi, J., Rhodes, M., Marquez, S. ve Velino, V. (2005). The incidence of false memories in native and non-native speakers. Memory, 13(8), 815-828. doi: 10.1080/09658210444000421.

Anastasi, J. S., De Leon, A. ve Rhodes, M. G. (2005). Normative data for semantically associated Spanish word lists that create false memories. Behavior Research Methods, 37(4), 631-637. doi: 10.3758/BF03192733.

Brainerd, C. J. ve Reyna, V. F. (2005). The science of false memory. New York: Oxford University Press.

Cadavid, S. ve Beato, M. S. (2017). False recognition in DRM lists with low association: A normative study. Psicologica: International Journal of Methodology and Experimental Psychology, 38(1), 133-147.

Cleary, A. M. ve Greene, R. L. (2002). Paradoxical effects of presentation modality on false memory. Memory, 10(1), 55-61. doi: 10.1080/09658210143000236.

Deese, J. (1959). On the prediction of occurrence of particular verbal intrusions in immediate recall. Journal of Experimental Psychology, 58, 17-22. doi: 10.1037/h0046671.

Dewhurst, S. A., Anderson, R. J. ve Knott, L. M. (2012). A gender difference in the false recall of negative words: Women DRM more than men. Cognition \& Emotion, 26(1), 65-74. doi: 10.1080/02699931.2011.553037. 
Dougal, S. ve Rotello, C. M. (2007). "Remembering" emotional words is based on response bias, not recollection. Psychonomic Bulletin \& Review, 14(3), 423-429. doi: 10.3758/BF03194083.

Gallo, D. A. (2004). Using recall to reduce false recognition: diagnostic and disqualifying monitoring. Journal of Experimental Psychology: Learning, Memory, and Cognition, 30(1), 120-128. doi: 10.1037/0278-7393.30.1.120.

Gallo, D. A. (2010). False memories and fantastic beliefs: 15 years of the DRM illusion. Memory \& Cognition, 38(7), 833-848. doi: 10.3758/MC.38.7.833.

Gallo, D. A., McDermott, K. B., Percer, J. M. ve Roediger, H. L. (2001). Modality effects in false recall and false recognition. Journal of Experimental Psychology: Learning, Memory, and Cognition, 27(2), 339-353. doi: 10.1037/0278-7393.27.2.339.

Gong, X., Xiao, H. ve Wang, D. (2016). Emotional valence of stimuli modulates false recognition: Using a modified version of the simplified conjoint recognition paradigm. Cognition, 156, 95-105. doi: 10.1016/j.cognition.2016.08.002.

Göz, İ. (2005). Word frequency effects in false memories. Psychological Reports, 96, 1095-1112.

Göz, İ., Karahan, S. K. ve Tekcan, A. İ. (2016). Individuals with obsessive-compulsive disorder are less prone to false memories. Journal of Obsessive-Compulsive and Related Disorders, 10, 62-68. doi: 10.1016/j.jocrd.2016.05.004.

Iacullo, V. M. ve Marucci, F. S. (2016). Normative data for Italian Deese/Roediger-McDermott lists. Behavior Research Methods, 48(1), 381-389. doi: 10.3758/s13428-015-0582-3.

Johansson, M. ve Stenberg, G. (2002). Inducing and reducing false memories: A Swedish version of the Deese-Roediger-McDermott paradigm. Scandinavian Journal of Psychology, 43(5), 369-383. doi: 10.1111/1467-9450.00305.

Kapucu, A., Kılıç, A., Özkılıç, Y. ve Sarıbaz, B. (2018). Turkish Emotional Word Norms for Arousal, Valence, and Discrete Emotion Categories. Psychological Reports, 0033294118814722. doi: 10.1177/0033294118814722.

Kapucu, A., Rotello, C. M., Ready, R. E. ve Seidl, K. N. (2008). Response bias in "remembering" emotional stimuli: A new perspective on age differences. Journal of Experimental Psychology: Learning, Memory, and Cognition, 34(3), 703-711. doi: 10.1037/0278-7393.34.3.703.

Kensinger, E. A. ve Schacter, D. L. (2008). Memory and emotion. Handbook of Emotions, 3, 601-617.

Maylor, E. A. ve Mo, A. (1999). Effects of study-test modality on false recognition. British Journal of Psychology, 90(4), 477-493. doi: 10.1348/000712699161567.

McCabe, D. P. ve Smith, A. D. (2002). The effect of warnings on false memories in young and older adults. Memory \& Cognition, 30(7), 1065-1077. doi: 10.3758/BF03194324.

McDermott, K. B. ve Roediger, H. L. (1998). Attempting to avoid illusory memories: Robust false recognition of associates persists under conditions of explicit warnings and immediate testing. Journal of Memory and Language, 39(3), 508-520. doi: 10.1006/jmla.1998.2582.

Misirlisoy, M. (2004). Effects of associative processes on false memory: Evidence from converging associates and category associates procedures. (Yayınlanmamış yüksek lisans tezi). Orta Doğu Teknik Üniversitesi, Ankara.

Norris, C. J., Leaf, P. T. veFenn, K. M.(2019). Negativity bias in false memory: Moderation by neuroticism after a delay. Cognition and Emotion, 33(4), 737-753. doi: 10.1080/02699931.2018.1496068.

Payne, D. G., Elie, C. J., Blackwell, J. M. ve Neuschatz, J. S. (1996). Memory illusions: Recalling, recognizing, and recollecting events that never occurred. Journal of Memory and Language, 35(2), 261-285. doi: 10.1006/jmla.1996.0015. 
Pierce, B. H., Gallo, D. A., Weiss, J. A. ve Schacter, D. L. (2005). The modality effect in false recognition: Evidence for test-based monitoring. Memory \& Cognition, 33(8), 1407-1413. doi: 10.3758/BF03193373.

Roediger, H. L. ve McDermott, K. B. (1995). Creating false memories: Remembering words not presented in lists. Journal of Experimental Psychology: Learning, Memory, and Cognition, 21(4), 803-814. doi: 10.1037/0278-7393.21.4.803.

Schneider, W., Eschman, A. ve Zuccolotto, A. (2012). E-Prime user's guide. Pittsburgh: Psychology Software Tools, Inc.

Smith, R. E. ve Hunt, R. R. (1998). Presentation modality affects false memory. Psychonomic Bulletin \& Review, 5(4), 710-715. doi: 10.3758/BF03208850.

Stadler, M. A., Roediger, H. L. ve McDermott, K. B. (1999). Norms for word lists that create false memories. Memory \& Cognition, 27(3), 494-500. doi: 10.3758/BF03211543.

Stein, L. M. ve de Azevedo Gomes, C. F. (2009). Brazilian norms for word lists: semantic association, concreteness, word frequency, and emotionality. Psicologia: Teoria e Pesquisa, 25(4), 537-546. doi: 10.1590/S0102-37722009000400009.

Stein, L. M. ve Pergher, G. K. (2001). Creating false memories in adults using word associated lists. Psicologia: Reflexão e Crítica, 14(2), 353-366. doi: 10.1590/S0102-79722001000200010.

Stein, L. M., Feix, L. D. F. ve Rohenkohl, G. (2006). Methodological advances in false memory research: Development and norming of DRM procedure. Psicologia: Reflexão e Crítica, 19(2), 166-176. doi: 10.1590/S0102-79722006000200002.

Şahin, G. (2011). Sahte hatıralarda işitsel modalite ile görsel modalite arasında ortaya çıkan farkın Sinyal Denetleme Teorisi ve güven aralıkları ile incelenmesi. (Yayınlanmamış Yüksek Lisans Tezi). Uludağ Üniversitesi, Bursa.

Şahin, G. ve Tekman, H. G. (2019). Remember/know and modality effects in a forced-choice test of false memory. Studies in Psychology, 39(1), 179-193. doi: 10.26650/SP2019-0016.

Tekcan, A. İ. ve Göz, İ. (2005) Türkçe kelime normlart: 600 Türkçe kelimenin imgelem, somutluk, sıklık değerleri ve çă̆rışım setleri. İstanbul: Boğaziçi Üniversitesi Yayınları.

Thapar, A. ve McDermott, K. B. (2001). False recall and false recognition induced by presentation of associated words: Effects of retention interval and level of processing. Memory \& Cognition, 29(3), 424-432. doi: 10.3758/BF03196393.

Thapar, A. ve Rouder, J. N. (2009). Aging and recognition memory for emotional words: A bias account. Psychonomic Bulletin \& Review, 16(4), 699-704. doi: 10.3758/PBR.16.4.699.

Ulatowska, J. ve Olszewska, J. (2013). Creating associative memory distortions-a Polish adaptation of the DRM paradigm. Polish Psychological Bulletin, 44(4), 449-456. doi: 10.2478/ppb-2013-0048.

Watson, J. M., Bunting, M. F., Poole, B. J. ve Conway, A. R. (2005). Individual differences in susceptibility to false memory in the Deese-Roediger-McDermott paradigm. Journal of Experimental Psychology: Learning, Memory, and Cognition, 31(1), 76-85. doi: 10.1037/0278-7393.31.1.76.

White, C. N., Kapucu, A., Bruno, D., Rotello, C. M. ve Ratcliff, R. (2014). Memory bias for negative emotional words in recognition memory is driven by effects of category membership. Cognition \& Emotion, 28(5), 867-880. doi: 10.1080/02699931.2013.858028.

Yüvrük, E., Kapucu, A. ve Turan, H. (2018, May1s). The role of emotion and working memory capacity on false memories (Poster sunumu). $2^{\text {nd }}$ International Meeting of Psychonomic Society, Amsterdam, Hollanda.

Zeelenberg, R. ve Pecher, D. (2002). False memories and lexical decision: Even twelve primes do not cause long-term semantic priming. Acta Psychologica, 109(3), 269-284. doi: 10.1016/S00016918(01)00060-9. 


\section{EK 1}

\begin{tabular}{|c|c|c|c|c|c|c|c|c|c|c|c|}
\hline \multirow{2}{*}{\multicolumn{2}{|c|}{$\begin{array}{l}\mathrm{KC} \\
\text { Uyku }(\% 79)\end{array}$}} & \multicolumn{10}{|c|}{ DRM LISTE SÖZCÜKLERİ } \\
\hline & & Rüya & Yatak & Gece & Yastık & Rahatlık & Horultu & Tulum & Derin & Bulut & Yorgan \\
\hline \multirow{9}{*}{ 츨 } & Çikolata (\%50) & Tatlı & Mutluluk & Siyah & Kahverengi & Lezzet & Şeker & Gofret & Findık & Yemek & Süt \\
\hline & Aile $(\% 69)$ & Anne & Baba & Beraberlik & Sicaklık & Güven & Yuva & Çekirdek & Birey & Toplum & Familya \\
\hline & Müzik (\%63) & Nota & Şarkı & Gitar & Dans & Melodi & Coşku & Kulak & Radyo & Saz & Zevk \\
\hline & Gülüş (\%40) & Diş & Kahkaha & Tebessüm & Espri & Gamze & Neşe & Komik & Samimiyet & Surat & Yanak \\
\hline & Barış (\%71) & Güvercin & Huzur & Beyaz & Antlaşma & Güzellik & Özgürlük & Zeytin dalı & İşaret & Dünya & Sükûnet \\
\hline & Tatil (\%71) & Deniz & Yaz & Dinlenme & Eğlence & Güneş & Havuz & Keyif & Heyecan & Sahil & Boşluk \\
\hline & Arkadaş (\%80) & Dost & Surdaş & Yakın & Kardeş & Yoldaş & Lise & Okul & Paylaşmak & Ahbap & Sadakat \\
\hline & Yavru (\%59) & Bebek & Çocuk & Köpek & Kuş & Kedi & Küçük & Minik & Evlât & Ufak & Şirin \\
\hline & Sevgi $(\% 67)$ & Așk & Bağlılık & Kalp & Sayg1 & Şefkat & Yürek & Hayat & Hoşgörü & Şiir & Emek \\
\hline \multirow{10}{*}{ 尝 } & Esir (\%55) & Savaş & Köle & Tutsak & Esaret & Mahkûm & Zincir & Kamp & Kırbaç & Asker & Aşıı \\
\hline & Cenaze (\%85) & Ölüm & Tabut & Üzüntü & Tören & Yas & Yeşil & Ağlama & Ceset & Dügŭün & Gözyaşı \\
\hline & Şüphe (\%46) & Kuşku & Kaygi & Paranoya & Ajan & Aldatmak & Dedektif & Endişe & Merak & Sanık & Sorgu \\
\hline & Israr (\%22) & İnat & Sıkıntı & Bıkkınlık & Gereksiz & Sıkıcı & Teklif & İtici & Sinir & Uğraş & Dayanılmaz \\
\hline & Yalan (\%67) & Yanlış & Doğru & Çirkin & İftira & Kandirmak & Pembe & Sahtelik & Söz & Yilan & Hile \\
\hline & Korkunç (\%82) & Film & Ürkütücü & Kötü & Hayalet & Karanlık & Dehşet & Canavar & Çığlık & İğrenç & Kâbus \\
\hline & İshal (\%40) & Tuvalet & Hastalık & $\mathrm{Su}$ & Kabız & Karm & Kahve & Bağırsak & Halsizlik & Kolera & Kusmak \\
\hline & Yangin $(\% 84)$ & Ateş & İtfaiye & Alârm & Kizil & Koku & Merdiven & Acil & Orman & Tehlike & Söndürmek \\
\hline & Cinayet $(\% 87)$ & Katil & Kan & Suç & Biçak & Ayrım & Hapis & Polis & Zanlı & Adlî tıp & Töre \\
\hline & Gürülttü (\%91) & Ses & Baş ağrısı & Patırt1 & Rahatsızlık & Kalabalık & Yorgunluk & Kargaşa & Kirlilik & Şehir & Trafik \\
\hline \multirow{17}{*}{ : } & Alet (\%63) & Edavat & Hurdavat & Tamirat & Makas & Tornavida & Çanta & Çekiç & Marangoz & Araç & Cihaz \\
\hline & İzlenim $(\% 38)$ & Gözlem & Görüş & Düşünce & Fikir & Bakış & Görünüm & Önyarg1 & İntiba & Etki & Gezi \\
\hline & Önem (\%45) & Değer & Ehemmiyet & Dikkat & İlgi & Ciddiyet & Öncelik & Uyarı & Vermek & Anlam & Bekleyiş \\
\hline & Giysi (\%55) & Elbise & Kuyafet & Pantolon & Alışveriş & Marka & Örtü & Dolap & Para & Ayakkab1 & Çıplak \\
\hline & Omuz (\%53) & Kol & Geniş & Sirt & Vatka & Ask & Atk1 & Vücut & Boyun & Çıkık & Erkek \\
\hline & Çabuk (\%56) & Hizlı & Acele & Ders & Atik & Koşmak & Sürat & Hemen & Kesmek & Saat & Tez \\
\hline & Balkon (\%58) & Ev & Manzara & Göbek & Teras & Çay & Masa & Saksı & Düşmek & Hava & Demir \\
\hline & $\operatorname{Araba}(\% 59)$ & Tekerlek & Ehliyet & Direksiyon & Konfor & Otomobil & Taksi & Anahtar & Benzin & Cip & Lâstik \\
\hline & Komşu (\%69) & Apartman & Yardım & Kap1 & Misafir & $\mathbf{K u z}$ & Dedikodu & Kül & Mahalle & Bahçe & Gerekli \\
\hline & Bina (\%80) & İnşaat & Yapı & Deprem & Beton & Daire & Yüksek & İş yeri & Kat & Mimar & Tuğla \\
\hline & \multicolumn{11}{|c|}{ KRİTIK OLMAYAN ÇELDİRICİLER } \\
\hline & \multicolumn{11}{|c|}{ POzíTiF } \\
\hline & İndirim & Ucuzluk & İskonto & & Sinema & Salon & Bilet & & Zeka & Akıl & Beyin \\
\hline & \multicolumn{11}{|c|}{ NEGATIF } \\
\hline & Kavga & Dövüş & Şiddet & & Soğuk & $\mathrm{K}_{1} s ̧$ & Kar & & Şok & Elektrik & Haber \\
\hline & \multicolumn{11}{|c|}{ NÖTR } \\
\hline & Kabin & Duş & Giyinmek & & Reklam & Televizyon & Tanitım & & İmza & İsim & Onay \\
\hline
\end{tabular}

Not: KÇ: Kritik Çeldirici. Kritik çeldiricilerin yanındaki parantez içindeki sayılar, söz konusu kritik çeldiricinin katılımcıların yüzde kaçı tarafindan yanlış alarm olarak tanındığını gösteren DRM etki yüzdeleridir. DRM liste sözcükleri, kritik sözcük ile çağrışım gücüne göre yüksekten düşüğe sıralanmıştrr. Koyu yazılan DRM liste sözcükleri, test aşamasında sunulan eski sözcüklerdir. 